Chapter 13

\title{
Applications of Ionic Liquids in Lignin Chemistry
}

\author{
Zhu Yinghuai, Karen Tang Yuanting and \\ Narayan S. Hosmane \\ Additional information is available at the end of the chapter \\ http://dx.doi.org/10.5772/51161
}

\section{Introduction}

\subsection{Lignin}

Lignin is a naturally occurring aromatic cross-linked polymer with molecular weight of more than 10,000 Daltons (Da). It is estimated that about $30 \%$ of the organic carbon in the earth's biosphere are from lignin [1,2]. It is made up of about $20-40 \%$ of wood and annual plants, depending on the species [1-3]. Together with cellulose and hemicellulose, they formed the lignocellulose, which is an important source of biomass. Lignocellulose is found largely in the cell walls with lignin acting as a linker between sets of cellulose and hemicellulose as shown in Figure 1. It is covalently bonded to hemicellulose, thus increasing the mechanical strength of the cell walls $[1,2,4]$. Due to its hydrophobicity, lignin prevents water from entering the cells; thus it provides an efficient way to transport water and nutrients by repelling them away from the cells. Hence, transportation cells such as tracheid, sclereid and xylem cells have more lignin in them [2].

\subsubsection{Monolignols}

As a natural polymer, lignin is made up of three main, but not limited to, basic monomers. These monomers are a variation of phenylpropane species collectively known as 'monolignols' which primarily includes $p$-coumaryl alcohol, coniferyl alcohol and sinapyl alcohol, shown in Figure 2 [3,5]. As observed from Figure 2, the structure of these monolignols differs only by the number of substituted methoxy group at the phenyl ring. Figure 2(a) has also shown the numbering system, based on lignin nomenclature rules, that is different and must not be confused with IUPAC nomenclature rules. 


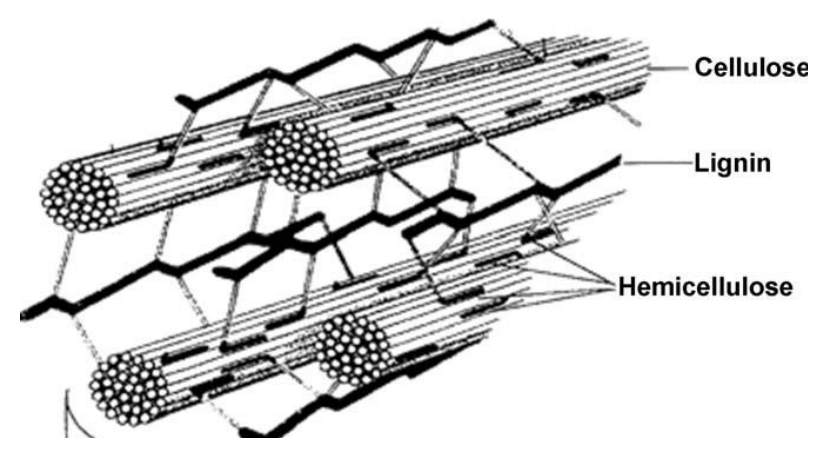

Figure 1. Lignocellulose network
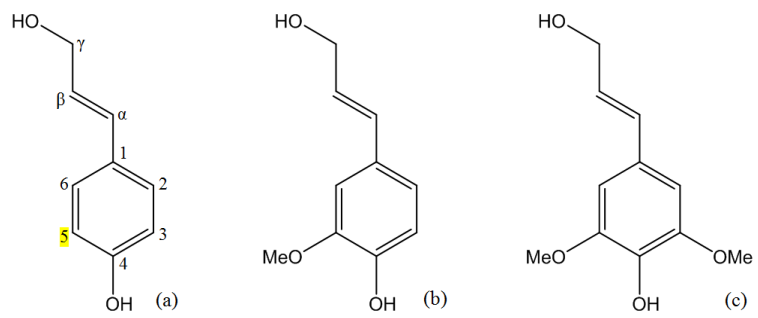

Figure 2. Lignin monomers: (a) p-coumaryl, (b) coniferyl and (c) sinapyl alcohols

Additionally, the composition of each lignin monomer differs significantly with the type of plant material, shown in Table 1. Softwood lignin, found in coniferous trees such as pine tree, composes of mainly of coniferyl alcohol and only a trace amount of sinapyl alcohol as their repeating units. On the other hand, hardwood lignin, found in tropical and subtropical trees such as oak and teak, contains both coniferyl and sinapyl alcohols in considerable amounts. It should also be noted that neither hardwood nor softwood lignin contains significant proportion of $p$-coumaryl alcohol which can be found in grass lignin along with other two monolignols.

\begin{tabular}{lccc}
\hline & $p$-Coumaryl alcohol & Coniferyl alcohol & Sinapyl alcohol \\
\hline Softwood & $<5$ & $<95$ & Trace amount \\
\hline Hardwood & $0-8$ & $25-50$ & $46-75$ \\
\hline Grasses & $5-33$ & $33-80$ & $20-54$ \\
\hline
\end{tabular}

Table 1. Compositions in monolignols in plant 


\subsubsection{Formation of Lignin}

From the monolignols, discussed above, it is apparent that lignin can be formed through phenylpropanoid, $p$-hydroxyphenyl, guaiacyl, and syringyl moieties by $p$-coumaryl, conifer$\mathrm{yl}$ and sinapyl alcohols, respectively.

The first step of the polymerization process involves oxidation of the monolignols forming a radical to initiate the reaction. Figure 3 shows the reaction and the various resonance structures of coniferyl alcohol radical formed [6]. Due to the various resonance structures, there is a randomness of bonding when radical coupling takes place. Table 2 shows the various common types of linkages that can be possibly formed. Out of the all linkages, the $\beta-\mathrm{O}-4$ linkage is the most common which make up $50-60 \%$ of the total linkages depending on the type of wood materials [2]. A simplified overall mechanism of the radical coupling of two coniferyl alcohols forming the $\beta$-O-4 linkage is shown in Figure 4 [6].

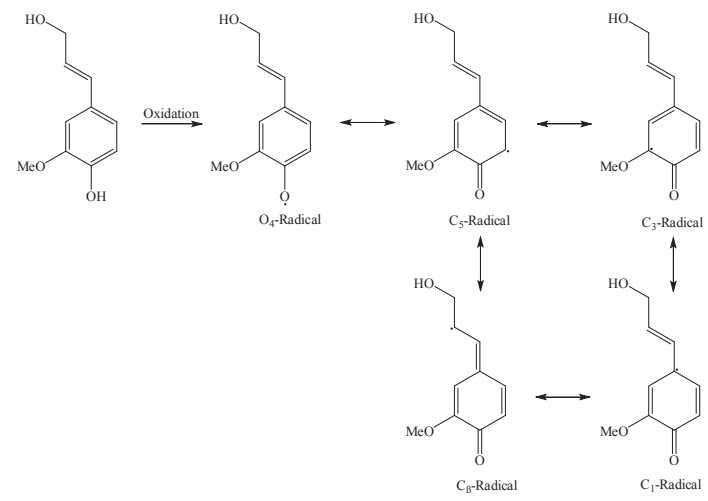

Figure 3. Oxidation of coniferyl alcohol

\begin{tabular}{lll}
\hline Name & Linkage \\
$\beta$-aryl ether & $\beta-\mathrm{O}-4$ \\
Phenylcoumaran & $\beta-5(\mathrm{a}-\mathrm{O}-4)$ \\
\hline
\end{tabular}




\begin{tabular}{|c|c|c|}
\hline Name & Linkage & Chemical Structure \\
\hline Resinol & $\beta-\beta(\alpha-\mathrm{O}-\alpha)$ & \\
\hline Biphenyl & $5-5$ & \\
\hline Biphenyl ether & $4-0-5$ & \\
\hline Benzodioxane & $\beta-O-4(a-O-5)$ & \\
\hline$\beta-C 1$ & $\beta-1$ & \\
\hline
\end{tabular}

Table 2. Common types of linkages
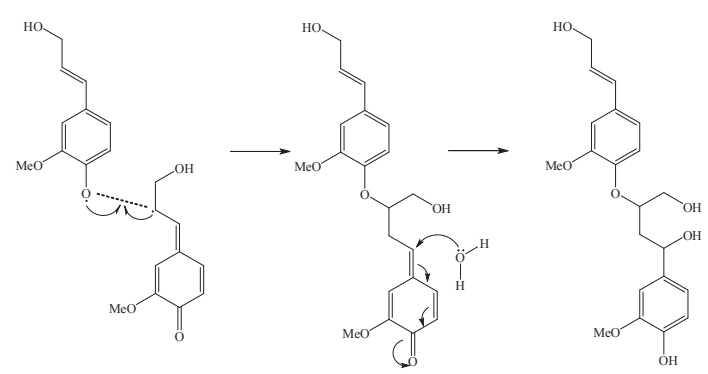

Figure 4. $\beta$-O-4 linkage formation via radical coupling of 2 coniferyl alcohols

It can be observed from Table 2 that the common types of linkages utilize most of the radicals formed in Figure 3 except for $\mathrm{C}_{3}$-radical. Radical coupling at the $\mathrm{C}_{3}$ site is just as likely to occur, but no stable product could be obtained (see Figure 5). Since the methoxyl group at the $\mathrm{C}_{3}$ site is a poor leaving group, the aromatic ring could not be regenerated. Thus, the coupling reaction will move backwards and the initial radicals can be obtained to form more stable linkages [6].

Due to the randomness in the bonding nature, the overall structure of the macromolecular lignin has not been accurately predicted. The overall 3D structure of lignin is also unknown as isolating them without modifications are still difficult even though better isolating methods are found [6]. 


\subsection{Ionic Liquids: Classifications and Synthetic Methods}

Ionic Liquids (ILs) are salts that are in liquid state. For example, sodium chloride $(\mathrm{NaCl})$ is an IL when it melts at $801^{\circ} \mathrm{C}$, forming sodium cations $\left(\mathrm{Na}^{+}\right)$and chloride anions $\left(\mathrm{Cl}^{-}\right)$. How ${ }^{-}$ ever, ILs of such high temperature cannot be used.Hence, in literature [7,8], ILs are usually referred to salts that are in liquid state at ambient temperatures $\left(<100{ }^{\circ} \mathrm{C}\right)$. They possess unique characteristics that distinguish them from molecular solvents. Many ILs are excellent prerequisities for efficient IL recycling as they have negligible vapour pressure and good thermal stability. Some of the ILs are very good solvents for large biomolecules, such as cellulose and lignin [9].

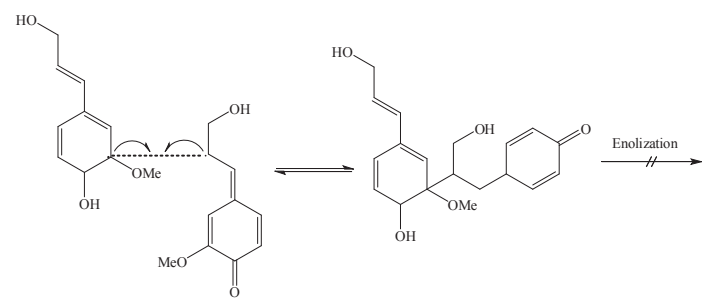

Figure 5. Possible but disallowed $C_{3}-C_{\beta}$ linkage

\subsubsection{Classifications of ILs}

Ionic liquids can be classified into many categories. Figure 6 shows one of the methods in which they are being classified.

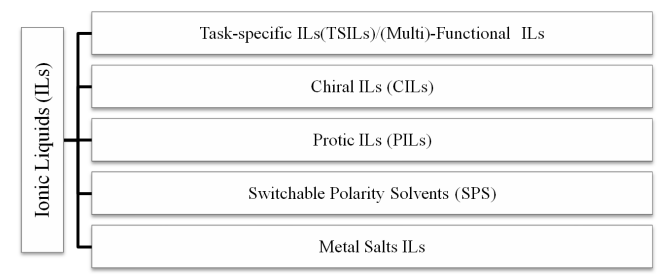

Figure 6. Various classes of ionic liquids

\subsubsection{Task-Specific ILs/ (Multi)-Functional ILs}

In the past decades, a vast amount of research has been performed to incorporate additional functional groups into functional ILs. This incorporation can introduce certain properties to ILs including enhancing capacity of catalyst reusability. In addition, when specific functionalities are added, the resulting IL will be task-specific, hence they are sometimes also referred as task-specific ILs (TSILs). Many of these TSILs are produced by introducing functional 
groups into a branch appended to the cation, especially imidazoliumcation (Figure 7). The imidazolium salts are only defined as TSILs when functional group is covalently bonded to the cation/anion of the salt, which behaves as a reaction medium and reagent/catalyst [10].

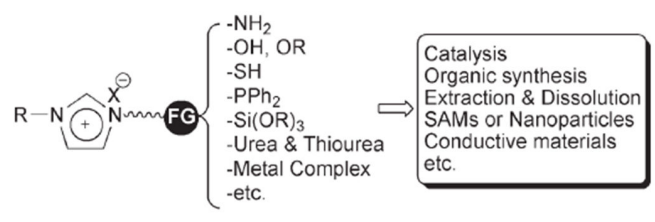

Figure 7. Functionalized imidazolium salts for task-specific ILs

\subsubsection{Chiral ILs}

Chiral ILs (CILs) are a special class of TSILs [11]. They have a chiral center either on the cation, anion or both. Due to their ease to synthesis, they had gained its popularity as a chiral solvent in asymmetric synthesis [12]. Figure 8 shows some examples of CILs.

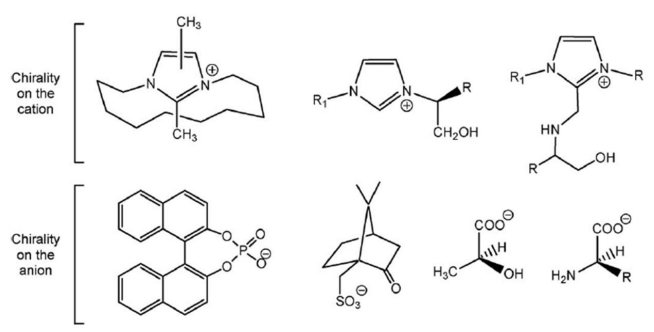

Figure 8. Examples of CILS.

\subsubsection{Protic ILs}

The major difference between Protic ILs (PILs) and other ILs is the presence of exchangeable proton. There is a resurrection of interest in these PILs recently due to their great capabilities for proton transfer in fuel cell chemistry. Some examples of PILs are shown in Figure 9. Many of these PILs are very strong acid, thus, the equilibrium is shifted heavily to the right. This, in terms, results in fully ionized ILs.

\subsubsection{Switchable Polarity Solvent (SPS)}

Switchable polarity solvents (SPS) equilibrate between a higher polarity and a lower polarity when trigger is applied. These solvents are particularly useful when two different polarities 
of the solvent are needed for two different steps. Recently, secondary amines have been used as SPS, with carbon dioxide as the trigger, forming carbamatesalts [13] (Figure 10).

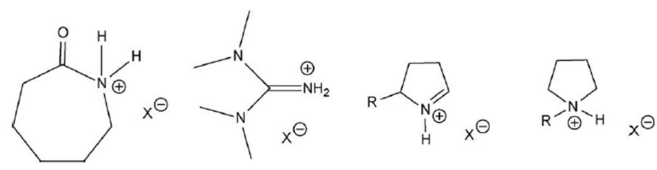

Figure 9. Some examples of PILs.

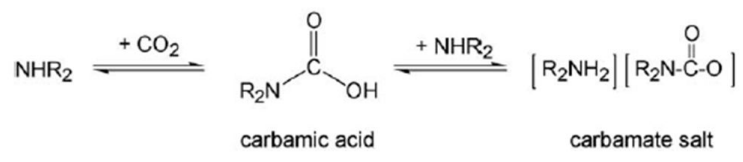

Figure 10. New generation of SPS.

\subsubsection{Metal Salts ILs}

Many metal salts ILs have been developed [15]. Chloroaluminates associating with imidazolium or pyridiumcations were part of a focused investigation, but was recently extended to include other chlorometalate salts (e.g. $\left.\left[\mathrm{CuX}_{3}\right]^{-},\left[\mathrm{NiCl}_{4}\right]^{2-},\left[\mathrm{Co}(\mathrm{CO})_{4}\right]^{-}\right)$. The recently developed chlorometalate salts are not water sensitive, unlike the chloroaluminates, but are generally more viscous. The introduction of the metal ions inside the ILs is able to immobilize catalysts while it is being the integral part of the potentially ordered structure of ILs.

\subsubsection{Preparations of ILs}

There are 4 main synthetic routes to prepare ILs. [7]. Figure 11 shows the overview of the synthetic methods.

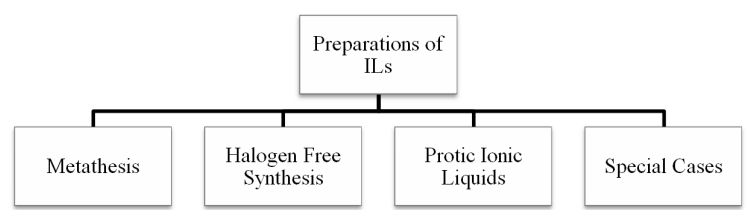

Figure 11. Synthetic routes of preparations of ILS 


\subsubsection{Metathesis}

Many ILs are prepared through a metathesis reaction from a halide or similar salt of the desired cation. This process can be subdivided into two classes depending on the water solubility of the targeted ILs. Figure 12 shows the overall reaction scheme of the metathesis reaction.

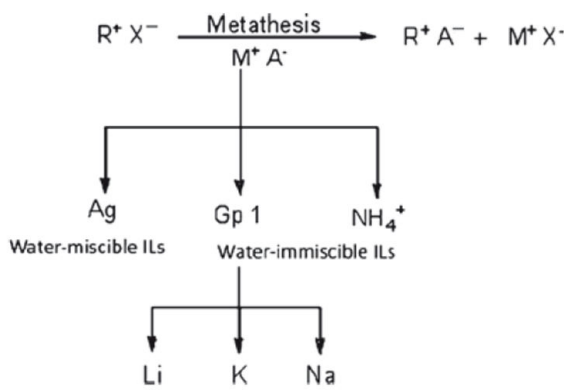

Figure 12. Overall metathesis routes to ILS

There are two main methods to prepare the water-immiscible ILs. The more commonly used approach is the metathesis reaction of the corresponding halide salt, using either the free anions of an acid or its salt. The use of free anions of an acid is favored as the hydrogen halide produced can be easily removed though washing with water. Alternatively, the metathesis reaction can also be conducted in organic solvents such as dichloromethane or acetone. However, the starting materials are not completely soluble and the reaction is carried out as a suspension. The organic layer must be washed several times with water to remove the unwanted halides.

The preparation of water-miscible ILs is proven to be more difficult as it requires purification steps before the desired ILs are obtained. This can be done easily by a metathesis reaction of the corresponding halide with a silver salt of the anion such as $\mathrm{AgBF}_{4}$. Unfortunately, this approach is not cost effective as large amount of silver halide is produced as a by-product. The ILs might also be silver-contaminated as complete precipitation of silver halides from organic solvents tends to be slow.

Ion exchange materials are also used to obtain ILs via the metathesis method although little information is available openly.

\subsubsection{Halogen Free Synthesis}

Production of high purity ILs via the metathesis method can be problematic due to contamination of the residual halide. The physical properties of the ILs can be drastically changed with the presence of the halides and may even result in catalyst poisoning and deactivation; hence, halide free synthetic methods had been devised. 
Imidazoles can be produced by using N-heterocyclic carbene (NHC) as its intermediate. Carbenes have a lone pair of electrons on a carbon atom which makes them very reactive. The synthesis of ILs via carbenes can be achieved by reacting with acids using either NHC adducts (Figure 13) or NHC-organometallic intermediates (Figure 14).

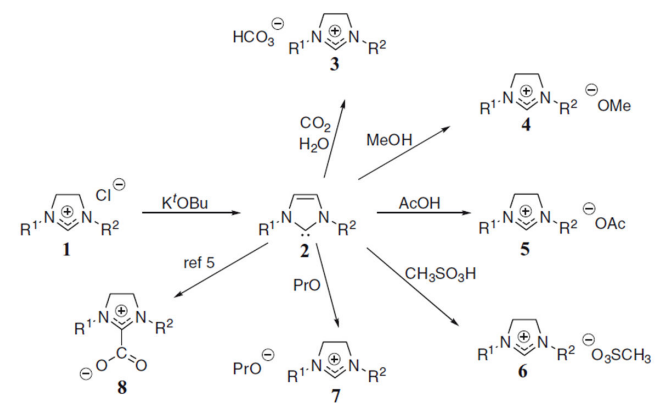

Figure 13. Synthetic methods of various ILs via NHC adducts

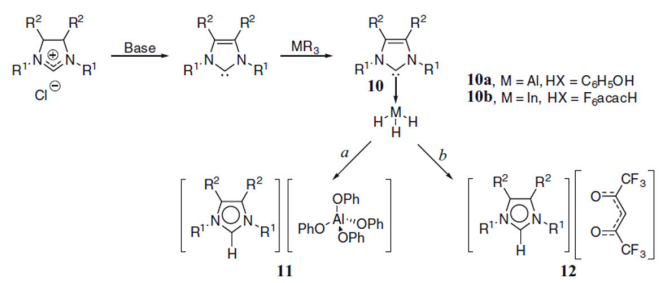

Figure 14. Reaction of NHC-organometallic intermediates with acids

Halogen-free phosphorus and sulfur based ILs can be produced by using the synthetic routes shown in Figure 15 and Figure 16 respectively.

\subsubsection{Protic Ionic Liquids (PILs)}

PILs can be synthesized by proton transfer between an equimolar mixture of a Brønsted acid and Brønsted base. This presents the advantage of being cost-effective and easily prepared as synthesis does not form residual products. PILs can produce hydrogen bonding between the acid and base or even hydrogen-bonded extended network.

\subsubsection{Special Cases}

Metal Based ILs

Transition metal complexes containing anions ILs were among the earliest developed room temperature ILs (RTILs). These RTILs can be synthesized by reaction of phosphonium/ 
imidazolium halides with metal halides or metathesis reaction with alkali salts of metal based anions. These metal based salts can be subdivided into three groups: transition metal, p-block and f-block metal salts.

\section{Functionalized ILs}

Till recently, functionalized ILs are prepared by displacement of halide from the organic halide containing the functional group by a parent imidazole, phosphine, etc., shown in Figure 17.

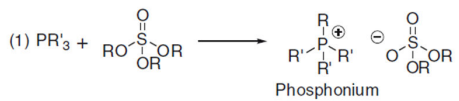

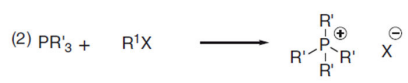

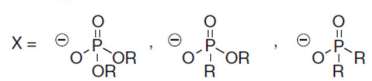

$$
\begin{aligned}
& \text { Phosphate Phosphonate Phosphinate }
\end{aligned}
$$

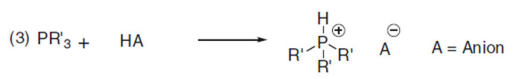

Figure 15. Halogen free synthetic routes for phosphonium ILs: (1) phosphines with sulphates; (2) $3^{\circ}$ phosphines or imidazoles with alkylating agents; (3) phosphines with acid.

a

$$
\text { b }
$$

Figure 16. Halogen free synthetic routes for (a) sulphate and (b) sulphonate ILs.

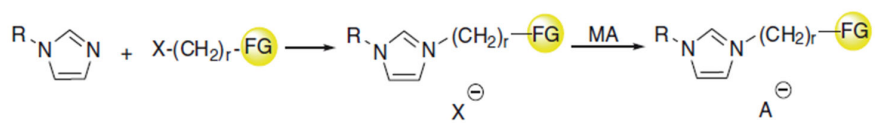

Figure 17. Classical method for functionalized ILs

Recently, novel functionalized ILs have been designed, synthesized and characterized. Some of the examples are:

- ILs with two Brønsted acid sites with $\mathrm{COOH}, \mathrm{HSO}_{4}$ or $\mathrm{H}_{2} \mathrm{PO}_{4}$ groups are synthesized by using methylimidazole with Brønsted acid moieties. 
- ILs with amino acids as anions are synthesized by neutralizing between [Emin][OH] and amino acid

- ILs with ether or alcohol functional groups are synthesized though alkylation of methylimidazole with alkyl halide, followed by halogen exchange with slight excess of $\mathrm{KPF}_{6}$ to reduce the remaining halogen content.

Microwave-Assisted

Using classical heating methods in reflux solvent, several hours of reaction time is needed to obtain reasonable yields. It also uses in large excess of alkylhalides and organic solvents. By using the microwave-assisted method, reaction time can be shortened with a cleaner workup procedure. However, ILs may decompose under such conditions.

\subsection{Ionic liquids in Lignin Chemistry: How compatible?}

As seen above, ILs are beneficial to a wide range of applications. These applications include, but not limited to, solvation, catalysis and as a reagent. In order to obtain lignin from plant, the ideal IL should possess properties as followed: (1) high dissolution capacity for lignin; (2) low melting point; (3) good thermal stability; (4) non-volatile; (5) non-toxic; (6) chemically stable; (7) no lignin decomposition; (8) easy lignin regeneration and (9) low cost and simple process [8]. For surface modifications and conversion of lignin to better materials, ILs can be used as a catalyst or solvent. In the next few sections, we will fully discuss in details of extracting lignin (Section 2), surface modification of lignin (Section 3) and conversion of lignin to value-added chemicals (Section 4) using ILs.

\section{Extracting Lignin with Ionic Liquid}

One of the most traditional methods to lignin extraction used in the industry is by the kraft process. Even though most of the lignin is extracted, it has several major disadvantages: (1) high temperature and pressure; (2) pollution; (3) odour problem (due to the use of sulphite); (4) high water usage and (5) large plant size [14].

Several other methods to extract lignin from lignocellulose have been designed and developed in the past. These include physical (limited pyrolysis and mechanical disruption/ comminution [15]), physiochemical (steam explosion, ammonia fiber explosion [16,17]), chemical (acid hydrolysis, alkaline hydrolysis, high temperature organic solvent pretreatment, oxidative delignification [18-20]) methods.These extraction methods have one main disadvantage: the lignin starts to degrade after a certain amount of lignin is extracted. This often leads to loss of fermentable sugars in the cellulose and hemicellulose, which can be used to produce other value-added products like the levulinic acid [21] and 5-hydroxymethylfurfural [22].

In the past decade, ILs have been used as solvents for natural polymers, including cellulose and starch [23-28] This leads to an interest in designing and developing ILs that are able to dissolve lignin and thus, extracting them from the lignocellulosic biomass. 


\subsection{Dissolution of Lignin}

$\mathrm{Pu}$ and co-workers [29] used the imidazoilum-based ILs for the studies of dissolution of residual softwood lignin isolated from a southern pine kraft pulp. Table 3 shows the solubility of the residual softwood lignin that they have obtained.

\begin{tabular}{lll}
\hline Ionic Liquid & Temperature $\left({ }^{\circ} \mathrm{C}\right)$ & Solubility $\left(\mathrm{g} \mathrm{L}{ }^{-1}\right)$ \\
\hline$[\mathrm{Mmim}]\left[\mathrm{MeSO}_{4}\right]$ & 50 & 344 \\
\hline$[\mathrm{Hmim}]\left[\mathrm{CF}_{3} \mathrm{SO}_{4}\right]$ & 25 & 74.2 \\
\hline$[\mathrm{Bmim}]\left[\mathrm{MeSO}_{4}\right]$ & 70 & 275 \\
\hline$[\mathrm{Bmim}][\mathrm{Cl}]$ & 50 & $<10$ \\
\hline$[\mathrm{Bmim}]\left[\mathrm{Br}^{2}\right]$ & 50 & 312 \\
\hline$[\mathrm{Bmim}]\left[\mathrm{PF}_{6}\right]$ & 25 & 61.8 \\
\hline$\left[\mathrm{Bm}{ }_{2} \mathrm{im}\right]\left[\mathrm{BF}_{4}\right]$ & 75 & 13.9 \\
\hline$[\mathrm{Bmpy}]\left[\mathrm{PF}_{6}\right]$ & 75 & 17.5 \\
\hline
\end{tabular}

Table 3. Solubility of residual softwood kraft pulp lignin in ionic liquids

They show that the lignin solubility can be influenced by the nature of anion as the solubility of the lignin differs when different $[\mathrm{Bmim}]^{+}$-containing ILs are used. They also concluded that ILs containing large, non-coordinating anions like $\left[\mathrm{PF}_{6}\right]^{-}$and $\left[\mathrm{BF}_{4}\right]^{-}$are not suitable for dissolving lignin; and that methylsulfateimidazolium-based ILs are effective for dissolution of residual softwood lignin isolated from a southern pine kraft pulp.

\subsection{Lignin Extraction without Dissolution of Biomass}

Lee and co-workers [30] had done lignin extraction from maple wood. They had also used Indulin AT (kraft lignin) as standards for solubility test. The results they had obtained are shown as Table 4. Using Indulin AT, the solubility of lignin shows similar results as Pu and co-workers as discuss earlier. However, when maple wood flour is used, there are difficulties dissolving and extracting lignin using the same ILs. Instead, $\mathrm{Cl}^{-}$-containing ILs, $[\mathrm{Amim}][\mathrm{Cl}]$ and $[\mathrm{Bmim}]$ $[\mathrm{Cl}]$, show better capabilities of extracting lignin from maple wood flour. This might be as a result of high solubility of the wood flour as a whole. $\mathrm{Cl}^{-}$ions are good hydrogen acceptors and are able to interact with the hydroxyl groups of the sugars, causing dissolution of cellulose too. They had also found an IL, [Emim] [Ac], that provides a balance between good lignin extraction and low wood flour solubility. Hence, lignin extraction can be done using [Emim][Ac] without much disruption of the cellulose and hemicellulose structures. 


$$
(\mathrm{g} / \mathrm{kg})^{\mathrm{c}}
$$

\begin{tabular}{lccc}
\hline$[\mathrm{Mmin}]\left[\mathrm{MeSO}_{4}\right]$ & $<500$ & $\mathrm{ND}$ & 0.8 \\
\hline$[\mathrm{Bmim}]\left[\mathrm{CF}_{3} \mathrm{SO}_{3}\right]$ & $<500$ & $\mathrm{ND}$ & 0.5 \\
\hline$[\mathrm{Emim}][\mathrm{AC}]$ & $<300$ & $<5$ & 4.4 \\
\hline$[\mathrm{Amim}][\mathrm{Cl}]$ & $<300$ & $<30$ & 5.2 \\
\hline$[\mathrm{Bmim}][\mathrm{Cl}]$ & $<100$ & $<30$ & 3.2 \\
\hline$[\mathrm{Bzmim}][\mathrm{Cl}]$ & $<100$ & $<10$ & 1.9 \\
\hline$[\mathrm{Bmim}]\left[\mathrm{BF}_{4}\right]$ & 40 & $\mathrm{ND}$ & $\mathrm{ND}$ \\
\hline$[\mathrm{Bmim}]\left[\mathrm{PF}_{6}\right]$ & $\sim 1$ & $\mathrm{ND}$ & $\mathrm{ND}$
\end{tabular}

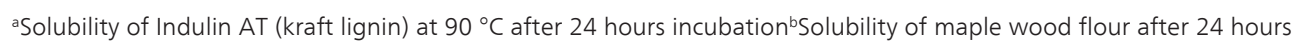
incubation at $80^{\circ} \mathrm{C}$ under $\mathrm{N}_{2}$, ND indicates $<1 \mathrm{~g} / \mathrm{kg}^{\mathrm{c}} 0.5 \mathrm{~g}$ maple wood flour was incubated in $10 \mathrm{~g}$ ILs for 24 hours at $80^{\circ} \mathrm{C}$ under $\mathrm{N}_{2}$. Lignin content was determined with Indulin AT standard. ND indicates $<0.1 \mathrm{~g} / \mathrm{kg}$

Table 4. Solubility and extraction efficiency of lignin in various ILs.

Another group, Tan, S. S. Y. et. al. [31], had reported of using the ethyl-methylimidazoliumalkylbenzenesulfonate IL, [Emim][ABS],for extraction of lignin from sugarcane bagasse. [Emim][ABS] was used for the study as sodium xylenesulfonate was used in a lesser known pulping process, hydrotropic pulping. Table 5 shows the lignin extraction increases with elevating temperature from $170{ }^{\circ} \mathrm{C}$ to $190{ }^{\circ} \mathrm{C}$, and when the extraction time increases from 30 minutes to 120 minutes. It should be noted that the mass recovered for Entry 3 is higher than the original lignin content. This might be due to the incorporation of the xylenesulfonate anion as sulphur is detected from the elemental analysis, which is not present in the original bagasse lignocelluloses. It might be also due to the reactions between lignin and hemicelluloses products. As a whole, lignin extraction with more than $93 \%$ yield was successfully attained at atmospheric pressure with [Emim][ABS]. Although ILs proved to be effective in the dissolution of lignin, several problems such as the simplification of IL recovery and designing an IL to create lignin with desirable adducts.

$\mathrm{Fu}$, Mazza and Tamaki [32] also reported that [Emim][Ac] is an effective solvent for lignin extraction from triticale straw, flax shives and wheat straw. Five other ILs ([Bmim][Cl], DMEAF, DMEAA, DMEAG, DMEAS) had been examined but the extraction yields are much lower than that of [Emim][Ac]. They had also investigated the extraction capabilities at a range of temperature $\left(70-150^{\circ} \mathrm{C}\right)$ and time taken $(0.5-24 \mathrm{~h})$. Results show that within this range, higher temperature and longer extraction time produces higher extraction yield.

\begin{tabular}{lll}
\hline Entry No. & Conditions & Mass of Recovered Lignina $(\% \pm 2)$ \\
\hline 1 & $170^{\circ} \mathrm{C}, 120 \mathrm{~min}$ & 67 \\
\hline 2 & $180^{\circ} \mathrm{C}, 120 \mathrm{~min}$ & 78 \\
\hline
\end{tabular}




\begin{tabular}{lll}
\hline Entry No. & Conditions & Mass of Recovered Lignin $(\% \pm 2)$ \\
\hline 3 & $190^{\circ} \mathrm{C}, 120 \mathrm{~min}$ & 118 \\
\hline 4 & $190^{\circ} \mathrm{C}, 90 \mathrm{~min}$ & 97 \\
\hline 5 & $190^{\circ} \mathrm{C}, 60 \mathrm{~min}$ & 96 \\
\hline 6 & $190^{\circ} \mathrm{C}, 30 \mathrm{~min}$ & 67 \\
\hline
\end{tabular}

${ }^{a}$ As percentage of original lignin content, corrected for ash content

Table 5. Mass of recovered lignin

Last year, Pinket and co-worker [33] published a paper that uses food additive-derived ILs, imidazoliumacesulfamate ILs, for lignin extraction from Pinus radiate and Eucalyptus nitenswood flour. They show promising results without disrupting the cellulose crystallinity. Among all, [Emim][Ace] is desirable for industrial processing due to its physical properties. The extracted lignins have a larger average molar mass as well as a more uniform molar mass distribution compared to that obtained from the Kraft process. This adds to another advantage of using imidazoliumacesulfamate ILs.

In their paper, they had also examined various extraction conditions: (1) Extraction temperature and time; (2) Water content; (3) Wood load, particle size and species; (4) Types of IL cation; (5) Effect of IL recycling; (6) Multi-step treatment and; (7) Use of co-solvents. Interestingly, the use of DMSO as a co-solvent $\left(w_{\mathrm{IL}}: w_{\mathrm{DMSO}}=9: 1\right)$ increases the extraction efficiency by almost $50 \%$ (Figure 18). It is believed that the penetration and interaction of the ligncellulosic biomass with IL is enhanced due to two effects caused by DMSO: (a) the tight hydrogen bond network of the cellulose is loosened and; (b) the overall viscosity of the mixture is decreased.

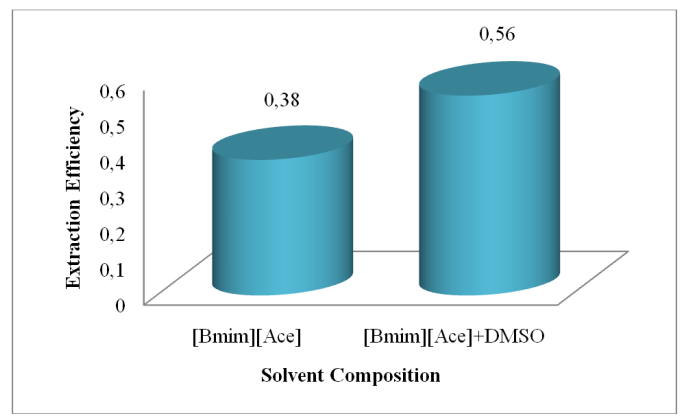

Figure 18. The extraction efficiency for extracting wood lignin with either pure [Bmim][Ace] or a mixture of [Bmim] [Ace] and DMSO ( $\left.w_{1 \mathrm{~L}}: W_{\mathrm{DMSO}}=9: 1\right)$. Pinusradiatawood flour $\left(w_{\mathrm{T}}=0.05\right)$, with particle size of $100 \mu \mathrm{m}$, was treated at $373 \mathrm{~K}$ for 2 hours in an open atmosphere.

Kim, J. et. al. [34] compared the structural features of poplar wood lignin extracted using IL, [Emim][Ac], and dioxane-water (classical method). Table 6 shows the summarized data ob- 
tained by them. It can be seen that a higher yield is obtained through IL extraction. Even though the lignins obtained from both extractions have relatively similar methoxy and phenolic hydroxyl contents, the molecular weight of that obtained from classical method is higher. However, the polydispersity index (PDI) of IL extraction is lower and thus, indicating that lignin from IL extraction is of rather uniform size. This suggests that some form of depolymerisation had occurred (will discuss further in Section 4.1) On top of that, thermal behaviour of the lignins were also analysed. Lignin obtained from classical method has a higher maximum decomposition rate and temperature, indicating that it is thermally more stable.

\begin{tabular}{lcc}
\hline & $\begin{array}{c}\text { Emim][Ac] } \\
\text { Extraction }\end{array}$ & Dioxane-water Extraction \\
\hline Yield (\%) & $5.8 \pm 0.3$ & $4.4 \pm 0.4$ \\
\hline Amount of OMe group (\%) & $15.5 \pm 1.5$ & $14.4 \pm 0.1$ \\
\hline Amount of phenolic $\mathrm{OH}$ group $(\%)$ & $6.7 \pm 0.2$ & $6.3 \pm 0.2$ \\
\hline Molecular Weight $(\mathrm{Da})$ & 6347 & 10,002 \\
\hline Polydispersity Index $(\mathrm{PDI})$ & 1.62 & 2.46 \\
\hline Max. decomposition rate $\left(\% /{ }^{\circ} \mathrm{C}\right)$ & 0.25 & 381.3 \\
\hline Max. decomposition temperature $\left({ }^{\circ} \mathrm{C}\right)$ & 308.2 & 30 \\
\hline
\end{tabular}

Table 6. Summarized data obtained by Kim, J. et. al. [34]

\subsection{Extraction of Lignin through Dissolution of Biomass}

Lignin extraction can also be done after complete dissolution of the whole cellulosic biomass. Lateef's group [35] demonstrated that cellulose-lignin mixture system can be separated and recovered from ILs, $[\mathrm{Pmim}][\mathrm{Br}]$ and $[\mathrm{Bmim}][\mathrm{Cl}]$. Cellulose precipitates when water is added to the solution (cellulose-lignin mixture in IL). Lignin is then recovered from the precipitate formed when the filtrate is treated with ethanol. The IL can be regenerated by evaporating the ethanol from the second filtrate with more than $95 \%$ yield. On the other hand, lignin yields of $69 \%$ and $49 \%$ were isolated from [Pmim] $[\mathrm{Br}]$ and [ $\mathrm{Bmim}][\mathrm{Cl}]$, respectively.

Muhammad and co-workers [36] used amino acid-based IL, [Emim][Gly], to dissolve bamboo biomass at $120^{\circ} \mathrm{C}$ in 8 hours. Other than [Emim][Gly], [Emim][TFA] and choline propionate were also investigated. [Emim][Gly] and choline propionate were used as it is reported that they have high hydrogen bond basicity. On the other hand, [Emim][TFA] was chosen as it contains an acetate-based anion which was proven for its dissolution of lignocelluloses. However, both [Emim][TFA] and choline propionate could not dissolve the bamboo biomass after 24 hours. Hence, only [Emim][Gly] was effective towards dissolution of bamboo biomass.

The lignin was then extracted from the solution using acetone/water mixture (7:3 ratio), obtaining about $85.3 \%$ of the total lignin content of the bamboo biomass. Acetone/water mixture acts as an anti-solvent of cellulosic materials and thus, precipitates cellulose and 
cellulose-rich materials. The acetone/water mixture ratio was determined using a plot of dissolved lignin (wt \%) against acetone/water ratio (v/v). It is shown that the amount of dissolved lignin is at the maximum when the acetone/water mixture ratio is 7:3.

Lan, Liu and Sun [37] performed a fractionation of bagasse to obtain cellulose $(47.17 \%)$, hemicellulose $(33.85 \%)$ and lignin $(54.62 \%)$, shown in Figure 19. They dissolved ball milled bagasse in $[\mathrm{Bmim}][\mathrm{Cl}]$ at $110^{\circ} \mathrm{C}$ under inert environment with agitation to obtain a clear solution. Residue 1 is regenerated using acetone/water $(9: 1, v / v)$ added to the clear solution. Filtrate 1 was then acidified to obtain Residue 2 (acetone soluble lignin). Residue 3 (cellulose) was extracted with $3 \%$ sodium hydroxide aqueous solution from Residue 1. Filtrate 3 was then treated with $4 \mathrm{M}$ hydrochloric acid and precipitated using 95\% ethanol to attain Residue 4 (hemicellulose). Filtrate 4 was acidified to obtain Residue 5 (Alkaline lignin).

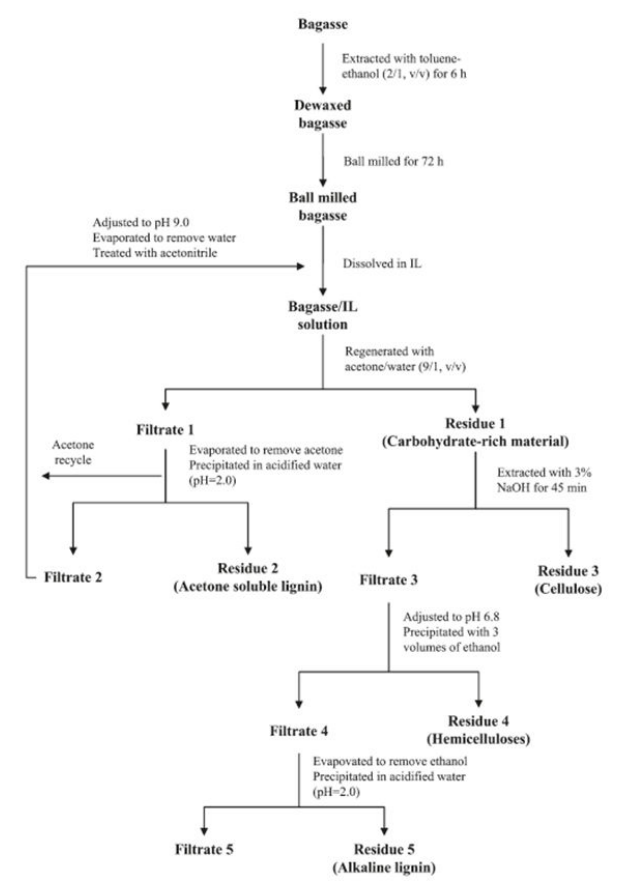

Figure 19. Schematic process of bagasse fractionation based on complete dissolution in $[\mathrm{Bmim}][\mathrm{Cl}]$ followed by precipitation in acetone/water $(9: 1, v / v)$ and extraction with $3 \% \mathrm{NaOH}$.

Sievers, C. et. al. [38] had recovered lignin fraction as a solid residue when IL phase hydrolysis of pine wood was done. They first dissolved pine wood in [Bmim][Cl]. Acid catalyst, trifluoroacetic acid, was subsequently added to convert the carbohydrate fraction to watersoluble products. These water-soluble products, which include furfural and 5-HMF, were then extracted using aqueous phase, leaving lignin as a solid. However, this method does 
not extract pure lignin and the lignin may be susceptible to modifications due to the acidic condition used.

Sun's group [39] dissolved both softwood and hardwood in [Emim][OAc] and lignin was extracted using acetone/water $(1: 1 \mathrm{v} / \mathrm{v})$. Figure 20 shows the ideal process flow of the dissolution and regeneration of wood in IL. However, recycling of IL was not investigated and evaluated in the published report. Although variable processes for lignin, similar to Pinket's [33], have been evaluated, but no report on dissolution of softwood and hardwood can be found. Sun's group evaluated the effects of (1) IL, (2) particle size, (3) wood species, (4) initial wood concentration and, (5) pretreatment. Using the same method as Muhammad's [36], they extracted lignin from the solution using acetone/water anti-solvent.

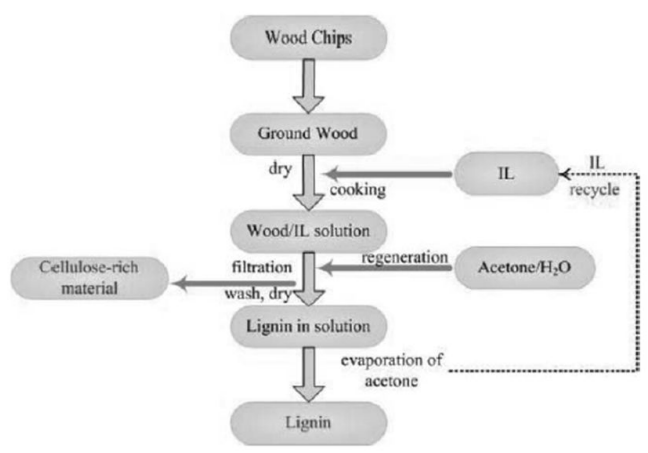

Figure 20. Flowchart for the process of dissolution and regeneration of wood in IL proposed by Sun's group

\section{Surface Modification of Lignin in Ionic Liquid Media to form Functional Materials}

Carbon fibres, activated carbon, polymer alloys, polyelectrolites, substituted lignins, thermosets, composites, wood preservatives, neutraceuticals/drugs, adhesives and resins are some macromolecules that can be obtained from lignin [40]. Some of them can be obtained from the extracted lignin directly, but most of them needed modifications. Surface modification of lignin allows a change in functional groups on the side-chains while maintaining the aromatic backbone of a lignin structure. Chemical modification of lignins (and also other lignocellulosic materials) leads to different structural characteristics [41]. In this section, we will discuss three types of surface modifications: oxidation, esterification and others.

\subsection{Oxidation}

Oxidation plays an important role in surface modification of lignin as hydroxyl groups are abundant. When these hydroxyl groups are oxidized, carbonyl groups are formed, which 
are more susceptible to reactions as compared to hydroxyl groups. In addition, it increases the hydrophilicty of lignin as well.

Zakzeski and co-workers [42] effectively performed oxidation of lignin using [Emim][DEP], cobalt catalyst and molecular oxygen. Although they had hypothesized that there will be an oxidative cleavage of $\beta$-O-4 linkage (will be discussed in details in Section 4 ) and other linkages, it did not materialize. Instead, the benzyl and other alcohol functionalities (i.e. hydrox$\mathrm{yl}$ groups at the side-chains) were oxidized to form aldehydes/acids. Similar results were obtained when the same reaction was done on various lignin model compounds, thus providing further evidences that the $\beta-\mathrm{O}-4$ linkage remained intact. Figure 21 shows the proposed scheme and various reaction sites of lignin when oxidation occurs. Mild conditions were used for the oxidation process due to the special properties of IL, which includes high oxygen solubility. The abundance of diethyl phosphate, [DEP], anions from the IL also allows simple metal salts to give exceptionally high activity.
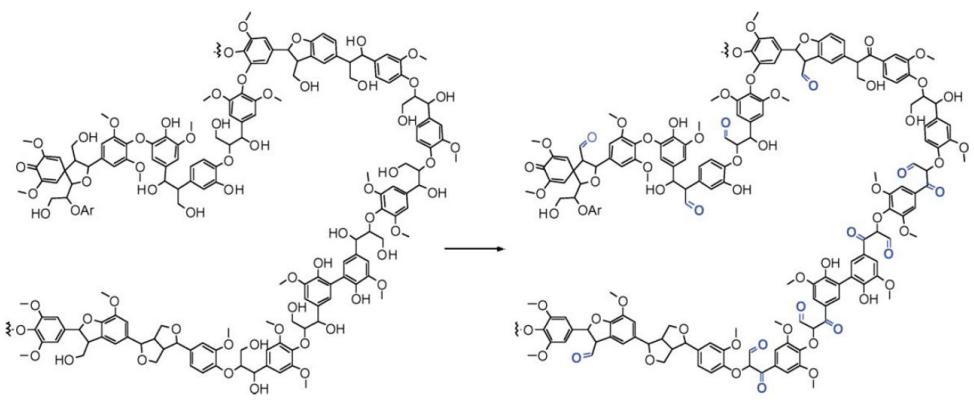

Figure 21. Proposed structure of lignin after oxidation

This Co/[Emim][DEP] catalyst system is able to increase the functionality and hydrophilicity of lignin, thus, Zakzeski had further investigated on the catalyst system [43]. Figure 22 shows the catalytic system proposed by them. As it can be seen, the hydroxyl group being oxidized will be coordinated to the cobalt catalyst forming a complex before oxidation takes place. Hence, the oxidation site must be acidic enough for the coordination to occur. This, in tern, explains why phenolic hydroxyl groups and the linkages were left untouched.

Similar oxidation reaction is done by Kumar, Jain and Chauhan [44] using water soluble iron (III) porphyrins and horseradish peroxidase (HRP) as catalyst, with hydrogen peroxide in IL. Figure 23 shows the reaction scheme that they had reported in their paper. Veratraldehydes are obtained as a major product for both catalysts with more than $70 \%$ yields when optimized. The non-coordinating nature and weak nucleophilicity of IL significantly enhances the activity of water soluble iron(III) porphyrins as compared to aqueous solutions. The stability of HRP is also improved when IL is used. Additionally, both catalysts can be recycled with appreciable activity for up to five runs. 


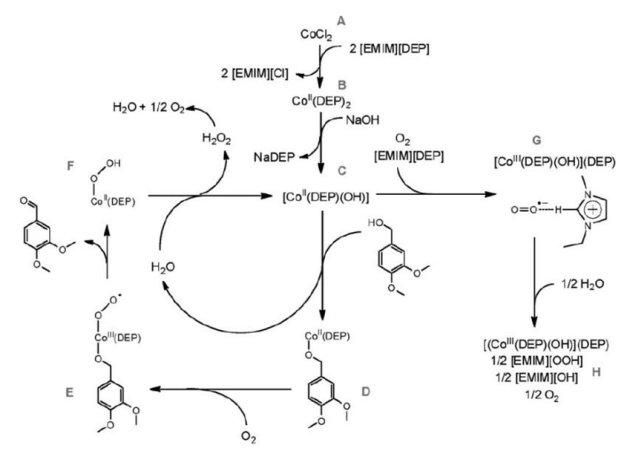

Figure 22. Proposed catalytic system using veratryl alcohol (lignin model compound) as substrate.

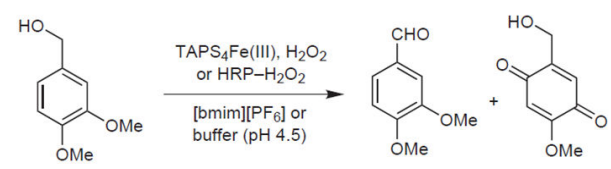

Figure 23. Reaction scheme reported by Kumar, Jain and Chauhan [44]

\subsection{Dehydration}

A stereospecific dehydration reaction was achieved by Kubo's group [45] by heat treatment in IL. A glycerol type enol-ether (EE), 3-(4-hydroxy-3-methoxyphenyl)-2-(2-methoxyphenoxy)-2-propenol, was produced from guaiacylglycerol- $\beta$-guaiacyl ether (GG) when temperature is increases to $120^{\circ} \mathrm{C}$, shown in Figure 24. The EE produced is previously believed to be an unstable intermediate in lignin degradation, but is obtainable as a stable compound in IL through this reaction. Furthermore, it is analyzed that the [Z] isomer of EE is formed as a major product.

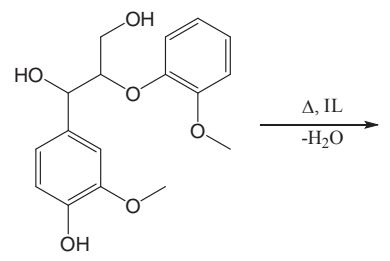<smiles>COc1cc(/C=C(/CO)Oc2ccccc2OC)ccc1O</smiles>

Figure 24. Stereospecific dehydration reaction achieved by Kubo's group [45] 


\subsection{Esterification}

Esterified wood displays admirable plastic properties such as highly substituted degree and excellent hydrophobicity. Hence, it is important to investigate possible esterification methods on wood.

Wen, J. et. al. [41] successfully carried out homogeneous lauroylation of ball-milled bamboo in IL. The ball-milled bamboo was first dissolved in IL, [Bmim][Cl], to enable separation of cellulose, lignin and hemicellulose. After complete dissolution, triethylamine and lauroyl chloride were added. Triethylamine was used to neutralize the hydrochloric acid generated during the esterification process. The bamboo ester was then regenerated. The whole reaction process is shown in Figure 25. Yuan and co-workers [46] had also achieved homogeneous lauroylation and butyrylation of poplar wood with a similar process. Xie's group [47] had also done a similar process, using pyridine instead of triethylamine as neutralizer, to attain homogeneous acetylation, benzoylation and carbanilation on thermomechanical pulp fibers.

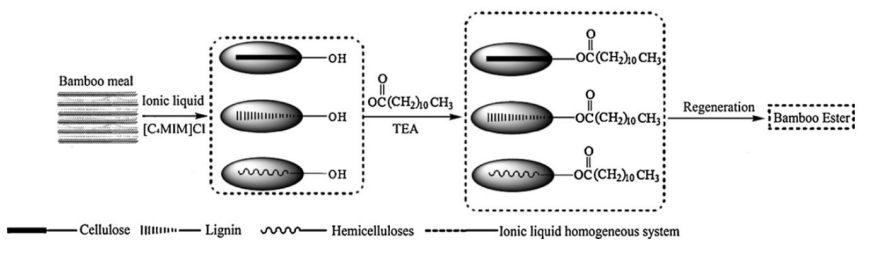

Figure 25. Schematic diagram of the dissolution and esterification process proposed by Wen, J. et. al. [41]

Cerrutti and co-workers [48] synthesized carboxymethyl lignin from organosolv lignin using monochloroacetic acid. An alkalinization of lignin, using sodium hydroxide, is performed before the carboxymethylation reaction to generate stronger nucleophiles for the reaction. The overall reaction is shown in Figure 26. One of the uses for this carboxymethyl lignin produced is as a stabilizing agent in aqueous ceramic suspension.

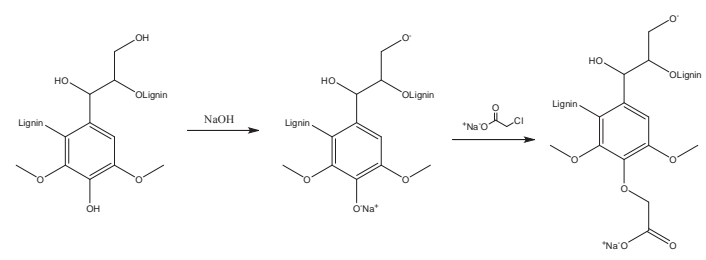

Figure 26. Overall reaction of carboxymethylation reaction

Using organosolv lignin as macro-initiator, Zhu, et al. successfully prepared polylactide-lignin hybrids with tin complex-based catalyst as detailed in Figure 27 [49]. High molecular weight copolymers with an Mw of ca. $5.3 \times 10^{4}$ (DPI 2.56) were produced in $77 \%$ yield. Results obtained from tensile strength testing showed that the tensile strength $\left(\sigma_{\mathrm{M}}, \mathrm{MPa}\right)$ was 
approximately doubled upon blending lignin with PLLA (PLLA:Lignin = 5:1; $\sigma_{\mathrm{M}}=11.3 \mathrm{MPa}$ ) and the ratio of 10:1 $\left(\sigma_{\mathrm{M}}=22.8 \mathrm{MPa}\right)$. There was also a significant increase in tensile modulus $\left(\mathrm{E}_{\mathrm{t}}\right)$ from 289 to $340 \mathrm{MPa}$ for blending ratios of 5:1 and 10:1, respectively. Tensile strength is the maximum stress that a material can withstand while being stretched before necking. Therefore, a increase in tensile strength indicates a tougher material.

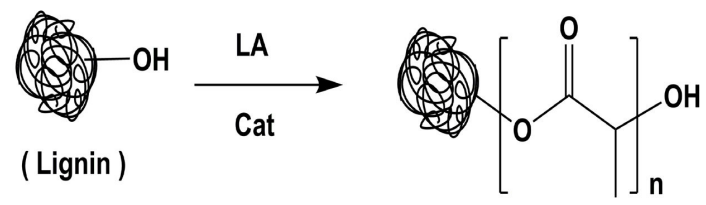

Figure 27. Synthesis of lignin-PLLA hybrid.

\section{Conversion of Lignin to Value-Added Chemicals in Ionic Liquid}

The lignin obtained from the biomass had be used mainly as a low value fuel in the past. [50-54] There are two main reasons for this main application. Firstly, harsh reaction conditions are required for depolymerization as the polyphenolic structure is chemically very stable. Adding on, the depolymerized products cannot be used as a substitute or additive for conventional liquid fuels due to its high oxygen content [50]. Secondly, biomass-derived feedstock are less readily available as compared to petroleum-derived feedstock. [50,51] However, due to rising fossil fuel prices and energy demand worldwide, research had turned towards obtaining value-added products from biomass-derived feedstock [51].

As mentioned in the introduction, lignin accounts for approximately $30 \%$ of organic carbon in the biosphere. Hence, it provides a promising platform for generation of value-added products from lignin [40], which is illustrated in Table 7.

\begin{tabular}{ll}
\hline Lignin & Syngas \\
Syngas Products & Methanol/Dimethyl ether, Ethanol, Mixed liquid fuels \\
Hydrocarbons & Cyclohexanes, higher alkylates \\
\hline Phenols & Cresols, Eugenol, Coniferols, Syringols \\
\hline Oxidized Products & Vanillin, vanillic acid, DMSO, aldehydes, Quinones, \\
& aromatic and aliphatic acids \\
\hline
\end{tabular}

Table 7. Value-added chemicals potentially derived from lignin.

Current strategies to produce these value-added chemicals from lignin are typically based on a two-step process. Firstly, lignin is depolymerized into simpler aromatic compounds. After depolymerization, some of the value-added chemicals can be obtained, e.g. phenols 
and oxidized products. Other value-added products are obtainable by transforming the resultant aromatic compounds. [55]

\subsection{Depolymerization of Lignin}

The macromolecular lignin contains various types of linkages, with $\beta$-O-4 ether linkage (50-60\% of total linkages) being the most common. Hence, one of the best depolymerization strategies is to target on cleavage of $\beta-\mathrm{O}-4$ ether linkage while preserving the aromatic character of the fragments [56]. Since it is difficult for researchers to determine and do mechanistic studies when macromolecular lignin is used, most of the papers uses lignin model compounds instead.

At the earlier stages of the research, Binder J. B. et. al. [57] shows that ILs provide a suitable medium for reactions of lignin model compounds. Through their various reactions done with several lignin model compounds, they suggested that not all model lignins are able to be used for depolymerization studies. Alkene-substituted aromatics and simple ethers are not suitable, being more reactive than natural lignin. While models like eugenol and 2-phenylethyl phenyl ether could be used, having similar reactivity trends as lignin, although they react under milder conditions than lignin.

Reichert and co-workers [58] successfully depolymerized lignin through electro-catalytic oxidative cleavage. They performed the depolymerization in the PIL, triethylammoniummethanesulfonate, using ruthenium-vanadium-titanium mixed oxide coated electrodes. The PIL offers a suitable medium for lignin dissolution, ensures higher potential electrolysis as well as promotes the oxidative cleavage mechanism as shown in Figure 28. They have also demonstrated that smaller molecular weight molecules are obtained when a higher applied potential is used.

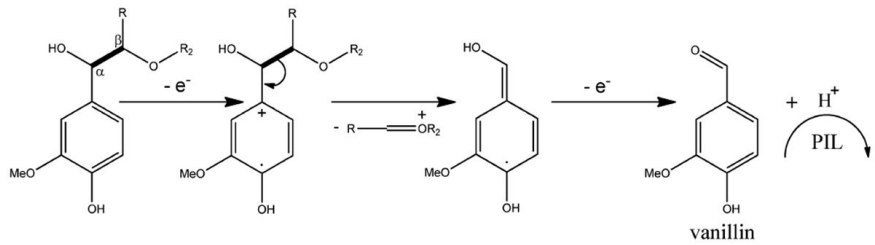

Figure 28. Mechanism of Oxidative cleavage of lignin at $C_{\alpha}-C_{\beta}$ bond

George, A. et. al. [59] observed that depolymerization occurs when various ILs are used to treat three types of technical lignins, organosolv, alkali and ALS lignins. They noted that the cation of ILs does not significantly affect the process. On the other hand, the size of the depolymerized lignin is decreased when sulfates $>$ lactate $>$ acetate $>$ chlorides $>$ phosphates are used as the anionic counterpart of ILs. Although no mechanistic studies have been done, there are indications that different anions cause cleavage at different linkages. Organosolv lignin, which is deemed closest to natural lignin, breaks down to smallest molecules, fol- 
lowed by ALS lignin and lastly alkali lignin. Organosolv lignin became more conjugated after treatment and thus, indicates a deconstruction mechanism consistent with that of an attack on strong nucleophile.

Jia's group [56] had demonstrated a method for the $\beta$-O-4 bond cleavage of two lignin model compound, guaiacylglycerol- $\beta$-guaiacyl ether (GG) and veratrylglycerol- $\beta$-guaiacyl ether (VG), in IL ([Bmim][Cl]) with metal chlorides. The simplified reaction scheme is shown in Figure 29. Iron(III) chloride, copper(II) chloride and aluminum(III) chloride are more effective in cleaving $\beta$-O-4 bond of GG. In this process, hydrochloric acid is formed. It was concluded that more $\beta-\mathrm{O}-4$ bond cleavage of GG occurs when there is an increase in available water. On the other hand, only aluminum(III) chloride is effective towards $\beta-\mathrm{O}-4$ bond cleaving of VG.

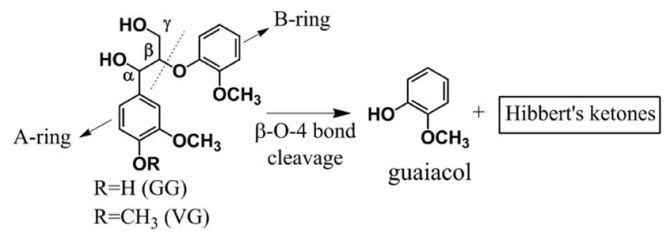

Figure 29. $\beta-O-4$ bond cleavage of GG and VG

Another group, Cox and co-workers [52], studied the Hammett acidity and anion effects of catalytic depolymerization of GG and VG in acidic imidazolium based IL. They had successfully used acidic ILs to hydrolyze the $\beta$-O-4 linkage. Although the acidic nature of ILs catalyzes the hydrolysis reaction, the Hammett acidity of ILs does not correlate with their reactivity toward GG and VG. The reactivity, however, is heavily dependent on the anion of the ILs. Hence, they postulated that the anion forms a hydrogen bond with GG and VG, making it more susceptible for hydrolysis (Figure 31).

\subsection{Value-added small molecular compounds}

After depolymerization, the products obtained can either be used directly or further processed to other value-added chemicals. Further processing in ILs have proven difficult even though they still serve as good solvents. For example, the colloidal catalyst, used by Bonilla [60], was inactivated for hydrogenation when IL, $[\mathrm{Bmim}]\left[\mathrm{BF}_{4}\right]$, was used. It was postulated that the IL itself caused the inactivation or the trace amount of chloride ions from the preparation of the IL is responsible.

Yan and co-workers [55] achieved the transformation of lignin-derived phenolic compounds to alkanes in ILs. The reaction system consists of metal (ruthenium, rhodium or platinum) nanoparticles and a $\mathrm{SO}_{3}$-functionalised Brønsted acid IL, which forms a catalytic cycle, in a non-functionalized IL, $[\mathrm{Bmim}]\left[\mathrm{BF}_{4}\right]$ or $[\mathrm{Bmim}]\left[\mathrm{TF}_{2} \mathrm{~N}\right]$, as solvent. This system allows hydro- 
genation and dehydration processes to occur in tadem, shown in Figure 32. Metal nanoparticles and the $\mathrm{SO}_{3}$-functionalised Brønsted acid IL were investigated while all others are kept constant. Rhodium, being the most active metal in benzene hydrogenation, is able to attain high alkane yields, even for branched phenols. It is also notable that methanol is produced when substrates with methoxy group are used. Various $\mathrm{SO}_{3}$-functionalized Brønstedacid ILs were examined. It was noticed that, in general, the stronger the acidity of the IL, the higher the obtainable yields. The exception being 1-(4-sulfobutyl)-3-methylimidazolium hydrogen sulphate, that has a Hammett acidity of around 1.75, resulting in a yield of over $80 \%$. It was predicted that the result is due to the dehydration power and poor nucleophilicity of the hydrogen sulphate anion.

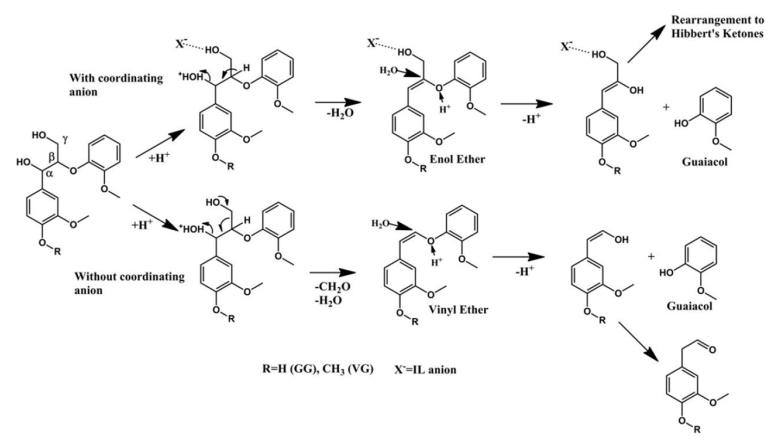

Figure 30. Mechanistic pathways of GG and VG degradation in acidic ILs.

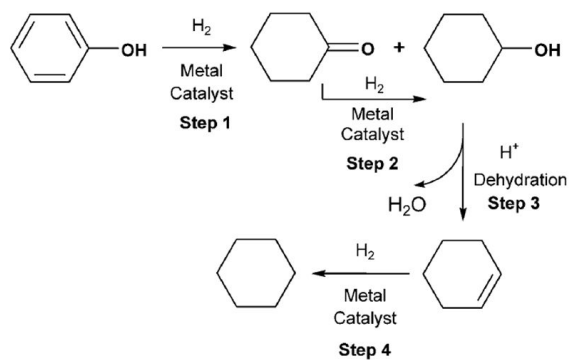

Figure 31. Reaction Scheme of cyclohexane from phenol

On the other hand, transition metal nanoparticle-based catalysts have been found to exhibit attractive catalytic activities relative to their corresponding bulk materials [61]. In our lab, ionic liquid stabilized metal nanoparticles have been found to be robust and recyclable catalyst composites for organic transformations [62]. Supported nano-Pd catalysts have been used as recyclable catalysts for alcohol oxidations [63-65]. Recently, the use of ionic liquid stabilized metal nanoparticles as catalysts have been employed in our group to conduct the 
oxidation conversion of lignin to value-added chemicals such as aromatic aldehydes (Figure 33) [66]. With a co-catalyst of pyridinium salt of iron bis(dicarbollide) (Figure 33), ionic liquid stabilized nano-Pd was found to be efficient for the oxidation of benzyl alcohol and lignin to produce aromatic aldehydes. The new $\operatorname{Pd}(0)$ catalytic system was found to be efficient, robust and recyclable with high product selectivity [66].

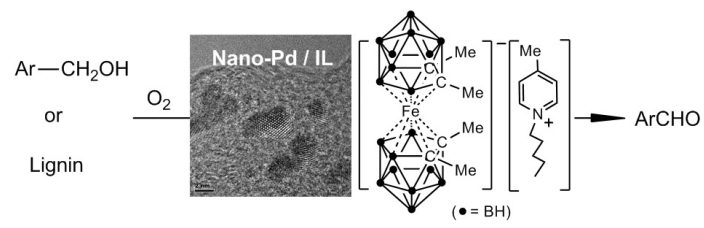

Figure 32. Application of IL stabilized nano-Pd in lignin oxidation reaction.

Also using rhodium nanoparticles, Denicourt-Nowicki and partners [67] successfully did hydrogenation on oxygen-containing arenes. Their rhodium nanoparticles are stabilized using polynitrogen ligands, like bipyridines. IL plays an interesting role in the reaction as it acts as both a solvent and a stabilizing agent. Hence, it has the ability to further stabilize the nanoparticles. One particularly interesting product obtained from the hydrogenation is the cyclohexanone from anisole (Figure 34). Cyclohexanone is used for synthesizing caprolactam and adipic acid, both of which are utilized in polyamides manufacturing. As shown in Figure 26, there are two plausible reaction pathways. The first pathway shows 1-methoxycyclohexene formed through the partial hydrogenation of anisole, then a hydrogenolysis into cyclohexen-1-ol, which results in the thermodynamically stable cyclohexanone. The second pathway demethylates anisole to phenol, followed by partial hydrogenation to obtain cyclohexen-1-ol, transforming to the thermodynamically stable cyclohexanone.

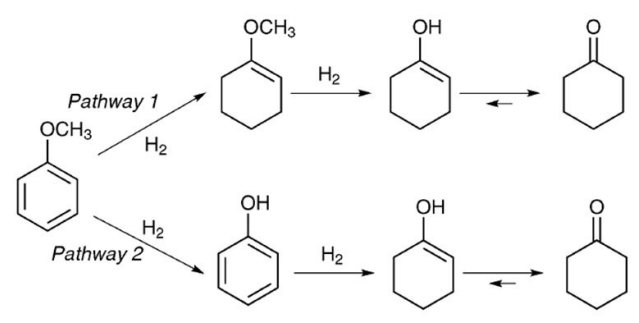

Figure 33. Potential pathways of anisole hydrogenation

Hydrogenation of acetophenone leads to several products and byproducts. This is primarily due to the competitive and consecutive hydrogenation of the carbonyl and aryl groups. Interesting selectivities were achieved when different ligand is used. Usage of 2,2'-bipyridine 
as a ligand produces an additional product, phenylethanol, which is not present when TPTZ (2,4,6-tris(2-pyridyl)-s-triazine) was used as the ligand. Hydrogenation of $o$ - and $m$-cresols leads to a mixture of methylcyclohexanols and methylcyclohexanone as products. It was noticed that the conversion of $o$-cresol is much slower than $m$-cresol. This can be explained by a kinetically less reactive disubstituted enol intermediate and also an increase in steric hindrance. Another point of notice is that the major products obtained are cis-isomers, just like the products obtained from normal heterogeneous catalytic systems.

\section{Conclusions and perspectives}

Lignin, which is estimated to be around 30\% of the biosphere carbon, is a naturally occurring aromatic cross-linked polymer. It is one of the three components of the lignocellulose. As lignin is able to dissolve in selective ionic liquids (ILs), it can be easily extracted from lignocellulose. There are mainly two methods of extraction and the main difference of the two methods is whether the whole lignocellulose is dissolved. The extracted lignin can then be chemically modified to form value-added chemicals. A surface modification of lignin is sufficient when macromolecular lignins are desired. Three types of surface modifications are discussed in this chapter which includes oxidation, dehydration and esterification. When smaller value-added molecules are desired, a depolymerization process should take place. Further transformation of the depolymerized lignin can also take place when the depolymerization step could not yield the desired product. As lignins, in any form, are able to dissolve in ILs, ILs become very good candidates as solvents. On top of having superior dissolution capabilities, ILs are considered as green solvents due to their non-volatility and low flammability. ILs are not only used as solvents but also play an important part in the catalytic cycles in some reactions discussed above. Hence, there is a surge in research in this area in the past five years.

As described above, the research on the applications of ILs in lignin chemistry is still at its budding stage, keen interest in developing this area will increase. As seen in this chapter, ILs are currently used in a small area of lignin chemistry. Since ILs are proven to be good solvents in lignin chemistry, they should be applied and used in other areas of lignin chemistry to create a greener and environmentally-friendly chemistry. However, ILs have a major shortcoming as they are much more expensive when compared to common and traditional solvents. Hence, recoverability of ILs should be explored and emphasized. Due to the $\pi-\pi$ interaction between ILs and lignin, removal of lignin from ILs are proven a complex process and, therefore, requires multiple steps [54]. This makes the recycling and regeneration of ILs, particularly in extremely large volumes, as cost inefficient. Therefore, this must also be addressed in future investigations in this area [68]. 


\section{Acknowledgements}

Special thanks are expressed to all researchers whose works have contributed in one way or the other to this chapter. Special gratitude is also given to the editor of the book, Dr Jun-ichi Kadokawa, for giving us the opportunity to contribute to the book. We thank ICES in Singapore for support of this work. NSH thanks the support by grants from the National Science Foundation (CHE-0906179 and CHE-0840504), Alexander von Humboldt Foundation, and the NIU Inaugural Board of Trustees Professorship Award.

\section{Author details}

Zhu Yinghuai ${ }^{1 *}$, Karen Tang Yuanting ${ }^{1}$ and Narayan S. Hosmane ${ }^{2}$

*Address all correspondence to: zhu_yinghuai@ices.a-star.edu.sg

1 Institute of Chemical and Engineering Sciences, No. 1 Pesek Road, Jurong Island, Singapore

2 Department of Chemistry and Chemical Biology, Northern Illinois University, DeKalb, Illinois 60115-2862, USA

\section{References}

[1] Boerjan, W., Ralph, J., \& Baucher, M. (2003). Lignin Biosynthesis. Annu. Rev. Plant Biol, 54, 519-546.

[2] Notley, S. M., \& Norgren, M. (2009). Lignin: Function Biomaterial with Potential in Surface Chemistry and Nanoscience. Nanoscience and Technology of Renewable Biomaterials; Lucia, L. A., Rojas O. J., Eds., Wiley \& Sons, United Kingdom, 173-206.

[3] Wang, J. S., Manley, R. S., \& Feldman, F. (1992). Synthetic-polymer Lignin Copolymer and Blends. Prog. Polym. Sci, 28, 271-282.

[4] Chabannes, M., Ruel, K., Yoshinaga, A., Chabbert, B., Jauneau, A., Joseleau, J., \& Boudet, A. (2001). Situ analysis of lignins in transgenic tobacco reveals a differential impact of individual transformations on the spatial patterns of lignin deposition at the cellular and subcellular levels. Plant $J$.

[5] Davin, L. B., Jourdes, M., Patten, A. M., Kim, K. W., Vassao, D. G., \& Lewis, N. G. (2008). Dissection of Lignin Macromolecular Configuration and Assembly: Comparison to Related Biochemical Processes. Allyl/Propenyl Phenol and Lignan Biosynthesis, Nat. Prod. Rep., 25, 1015-1090. 
[6] Dimmel, D. (2010). Overview. Lignin and Lignans: Advances in Chemistry; Heither, C., Dimmel, D. R., Schmidt, J. A., Eds., CRC Press, Boca Raton, 1-10.

[7] Clare, B., Sirwardanam, A., \& Mac, Farlane. D. R. (2009). Synthesis, Purification and Characterization of Ionic Liquids. Top. Curr. Chem., 209, 1-40.

[8] Olivier-Bourbigou, H., Magna, L., \& Morvan, D. (2010). Ionic liquids and catalysis: Recent progress from knowledge to applications. Appl. Catal. A,, 373, 1-56.

[9] Lee, S. (2006). Functionalized imidazolium salts for task-specific ionic liquids and their applications. Chem. Commun., 1049-1063.

[10] Winkel, A., Reddy, P. V. G., \& Wilhelm, R. (2008). Recent Advances in the Synthesis and Application of Chiral Ionic Liquids. Synthesis, 7, 999-1016.

[11] Baudequinm, C., Baudoux, J., Levillian, J., Cahard, D., Gaumont, A., \& Plaquevent, J. Ionic Liquids and chirality: opportunities and challenges. Tetrahedron: Asymmetry (2003). (14), 3081-1093.

[12] Phan, L., Andreatta, J. R., Horvey, L. K., Edie, C. F., Luco, A., Mirchandani, A., Darensbourg, D. J., \& Jessop, P. G. (2008). Switchable-Polarity Solvents Prepared with a Single Liquid Component. J. Org. Chem., 73, 127-132.

[13] Lin, I. J. B., \& Vasam, C. S. (2005). Metal-containing ionic liquids and ionic liquid crystals based on imidazolium moiety. J. Organomet. Chem. [690], 3498-3512.

[14] Wegener, G. (1992). Pulping innovations in Germany. Ind. Crops Prod. [1], 113-117.

[15] Mosier, N., Wyman, C., Dale, B., Elander, R., Lee, Y. Y., Holtzapple, M., \& Ladisch, M. (2005). Features of promising technologies for pretreatment of lignocellulosic biomass. Bioresour. Technol. [96], 673-686.

[16] Grous, W. R., Converse, A. O., \& Grethlein, H. E. (1986). Effect of steam explosion pretreatment on pore size and enzymatic hydrolysis of poplar. Enzyme Microb. Technol., 8, 274-280.

[17] Mes-Hartree, M., Dale, B. E., \& Craig, W. K. (1988). Comparison of steam and ammonia pretreatment for enzymatic hydrolysis of cellulose. Appl. Microbiol. Biotechnol. , $29,462-468$.

[18] Chum, H. L., Johnson, D. K., Black, S., Baker, J., Grohmann, K., Sarkanen, K. V., Wallace, K., \& Schroeder, H. A. (1988). Organosolv pretreatment for enzymatic hydrolysis of poplars: I. Enzyme hydrolysis of cellulosic residues. Biotechnol. Bioeng., 31, 643-649.

[19] Zhang, Y. H. P., Ding, S. Y., Mielenz, J. R., Cui, J. B., Elander, R. T., Laser, M., Himmel, M. E., Mc Millan, J. R., \& Lynd, L. R. (2007). Fractionating recalcitrant lignocellulose at modest reaction conditions. Biotechnol. Bioeng., 97, 214-223.

[20] Gierer, J., \& Norén, I. (1982). Oxidative Pretreatment of Pine Wood to Facilitate Delignification during Kraft Pulping. Holzforschung, 36, 123-130. 
[21] Vyver, S. V., Thomas, J., Geboers, J., Keyzer, S., Smet, M., Dehaen, W., Jacobs, P. A., \& Sels, B. F. (2011). Catalytic production of levulinic acid from cellulose and other biomass-derived carbohydrates with sulfonatedhyperbranched poly(aryleneoxindole)s. Energy Environ. Sci. [4], 3601-3610.

[22] Román-Leshkov, Y., Chheda, J. N., \& Dumesic, J. A. (2006). Phase Modifiers Promote Efficient Production of Hydroxymethylfurfural from Fructose. Science [312], 1933-1937.

[23] Swatloski, R. P., Spear, S. K., Holbrey, J. D., \& Rogers, R. D. (2002). Dissolution of cellulose with ionic liquids. J. Am. Chem. Soc. [124], 4974-4975.

[24] Liu, Q., Janssen, M. H. A., Van Rantwijk, F., \& Sheldon, R. A. (2005). Room-temperature ionic liquids that dissolve carbohydrates in high concentrations. Green Chem. [7], 39-42.

[25] Moulthrop, J. S., Swatloski, R. P., Moyna, G., \& Rogers, R. D. High-resolution 13C NMR studies of cellulose and cellulose oligomers in ionic liquid solutions. Chem. Commun., 1557-1559.

[26] Fort, D. A., Swatloski, R. P., Moyna, P., Rogers, R. D., \& Moyna, G. (2006). Use of ionic liquids in the study of fruit ripening by high-resolution 13C NMR spectroscopy: "green" solvents meet green bananas. Chem. Commun., 714-716.

[27] Zhu, S., Wu, Y., Chen, Q., Yu, Z., Wang, C., Jin, S., Ding, Y., \& Wu, G. (2006). Dissolution of cellulose with ionic liquids and its application: A mini-review. Green Chem. [8], 325-327.

[28] Fort, D.A., Remsing, R.C., Swatloski, R.P., Moyna, P., Moyna, G., \& Rogers, R.D. (2007). Can ionic liquids dissolve wood? Processing and analysis of lignocellulosic materials with 1-n-butyl-3-methylimidazolium chloride. Green Chem., 9, 63-69.

[29] Pu, Y., Jiang, N., \& Ragauskas, A. J. (2007). Ionic Liquid as a Green Solvent for Lignin. J. Wood Chem.Technol., 27, 23-33.

[30] Lee, S. H., Doherty, T. V., Linhardt, R. J., \& Dordick, J. S. (2009). Ionic liquid-mediated selective extraction of lignin from wood leading to enhanced enzymatic cellulose hydrolysis. Biotechnol. Bioeng., 102, 1368-1376.

[31] Tan, S. S. Y., Mac, Farlane. D. R., Upfal, J., Edye, L. A., Doherty, W. O. S., Patti, A. F., Pringle, J. M., \& Scott, J. L. (2009). Extraction of lignin from lignocellulose at atmospheric pressure using alkylbenzenesulfonate ionic liquid. Green Chem., 11, 339-345.

[32] Fu, D., Mazza, G., \& Tamaki, Y. (2010). Lignin Extraction from Straw by Ionic Liquids and Enzymatic Hydrolysis of the Cellulosic Residues. J. Agric. Food Chem. [58], 2915-2922.

[33] Pinkert, A., Goeke, D. F., Marsh, K. N., \& Pang, S. (2011). Extracting wood lignin without dissolving or degrading cellulose: investigations on the use of food additives-derived ionic liquids. Green Chem. [13], 3124-3136. 
[34] Kim, J., Shin, E., Eom, I., Won, K., Kim, Y. H., et al. (2011). Structural features of lignin macromolecules extracted with ionic liquid from poplar wood. Bioresour. Technol. [102], 9020-9025.

[35] Lateef, H., Grimes, S., Kewcharoenwong, P., \& Feinberg, B. (2009). Separation and recovery of cellulose and lignin using ionic liquids: a process for recovery from paperbased waste. J. Chem. Technol. Biotechnol. [84], 1818-1827.

[36] Muhammad, N., Man, Z., Bustam, M. A., Mutalib, M. I. A., Wilfred, C. D., \& Rafiq, S. (2001). Dissolution and Delignification of Bamboo Biomass Using Amino Acid-Based Ionic Liquid. Appl. Biochem. Biotechnol. [165], 998-1009.

[37] Lan, W., Liu, C., \& Sun, R. (2011). Fractionation of Bagasse into Cellulose, Hemicelluloses, and Lignin with Ionic Liquid Treatment Followed by Alkaline Extraction. J. Agric. Food Chem. [59], 8691-8701.

[38] Sievers, C., Valenzula-Olarte, M., Marzialetti, T., Musin, I., Agrawal, P. K., \& Jones, C. W. (2009). Ionic-Liquid-Phase Hydrolysis of Pine Wood. Ind. Eng. Chem. Res., 48, 1277-1286.

[39] Sun, N., Rahman, M., Qin, Y., Maxim, M. L., Rodríguez, H., \& Rogers, R. D. (2009). Complete dissolution and partial delignification of wood in the ionic liquid 1-ethyl-3methylimidazolium acetate. Green Chem. [11], 646-655.

[40] Menon, V., \& Rao, M. (2012). Trends in bioconversion of lignocellulose: Biofuels, platform chemicals \&biorefinery concept. Prog. Energy Combust. Sci., 1-29.

[41] Wen, J., Sun, Y., Meng, L., Yuan, T., Xu, F., \& Sun, R. (2011). Homogeneous lauroylation of ball-milled bamboo in ionic liquid for bio-based composites production Part I; Modification and characterization. Ind. Crops Prod. [34], 1491-1501.

[42] Zakeski, J., Jongerius, A. L., \& Weckhuysen, B. M. Transition metal catalyzed oxidation of Alcell lignin, soda lignin, and lignin model compounds in ionic liquid. Green Chem. (2010). , 2010(12), 1225-1236.

[43] Zakeski, J., Bruijninex, P. C. A., \& Weckhuysen, B. M. (2011). In situ spectroscopic investigation of the cobalt-catalyzed oxidation of lignin model compounds in ionic liquids. Green Chem. [13], 671-680.

[44] Kumar, A., Jain, N., \& Chauhan, S. M. S. (2007). Biomimetic Oxidation of Veratryl Alcohol with $\mathrm{H}_{2} \mathrm{O}_{2}$ Catalyzed by Iron(III) Porphyrins and Horseradish Peroxidase in Ionic Liquid. Synlett [3], 411-414.

[45] Kubo, S., Hashida, K., Yamada, T., Hishiyama, S., Magara, K., et al. (2008). A Characteristic Reaction of Lignin in Ionic Liquids; Glycelol Type Enol-Ether as the Primary Decomposition Product of $\beta$-O-4 Model Compound. J. Wood Chem. Technol., 28, 84-96.

[46] Yuan, T., Sun, S., Xu, F., \& Sun, R. (2011). Homogeneous butyrylation and lauroylation of poplar wood in the ionic liquid 1-butyl-3methylimidazolium chloride. Bioresour. Technol. [102], 4590-4593. 
[47] Xie, H., King, A., Kilpelainen, I., Granstrom, M., \& Argyropoulos, D. S. (2007). Thorough Chemical Modification of Wood-Based Lignocellulosic Materials in Ionic Liquids. Biomacromolecules [8], 3740-3748.

[48] Cerrutti, B.M., de Souza, C.S., Castellan, A., Ruggiero, R., \& Frollini, E. (2012). Carboxymethyl lignin as stabilizing agent in aqueous ceramic suspensions. Ind. Crops Prod., 36, 108-115.

[49] Zhu, Y., Yang, S.H., \& Tham, Y.H. Polymer composites cored with lignin. 3rd EuCheMS Chemistry Congress, 29 August-2 September, Numberg, Germany.

[50] Kleinert, M., \& Barth, T. (2008). Phenol from Lignin. Chem. Eng. Technol., 31(5), 736-745.

[51] Clark, J. H., Deswarte, F. E. I., \& Farmer, T. J. (2009). The integration of green chemistry. Biofuels, Bioprod. Biorefin. [3], 72-90.

[52] Cox, B. J., Jia, S., Zhang, Z. C., \& Ekerdt, J. G. (2011). Catalytic degradation of lignin model compounds in acidic imidazolium based ionic liquids: Hammett acidity and anion effects. Polym. Degrad. Stab. [96], 426-431.

[53] Holladay, J. E., White, J. F., Bozell, J. J., \& Johnson, D. Top Value-Added Chemicals from Biomass- Volume II-Results of Screening for Potential Candidates from Biorefinery Lignin. Pacific Northwest National Laboratory Richland, WA. (2007).

[54] Zakzeski, J., Bruijnincx, P. C., Jongerius, A. L., \& Weckhuysen, B. M. (2010). The catalytic valorization of lignin for the productionof renewable chemicals. Chem. Rev., 3552-3599.

[55] Yan, N., Yuan, Y., Dykeman, R., Kou, Y., \& Dyson, P. J. (2010). Hydrodeoxygenation of Lignin-Derived Pehnols into Alkanes by Using Nanoparticles Catalysts Combined with Brønsted Acidic Ionic Liquids. Angew. Chem. Int. Ed. [49], 5549-5553.

[56] Jia, S., Cox, B. J., Guo, X., Zhang, Z. C., \& Ekerdt, J. G. (2011). Hydrolytic cleavage of $\beta-\mathrm{O}-4$ ether bonds of lignin model compounds in an ionic liquid with metal chlorides. Ind. Eng. Chem. Res. [50], 849-855.

[57] Binder, J. B., Gray, M. J., White, J. F., Zhang, Z. C., \& Halloday, J. E. (2009). Reactions of lignin model compounds in ionic liquids. BiomassBioenergy [33], 1122-1130.

[58] Reichert, E., Wintringer, R., Volmer, D. A., \& Hempelmann, R. (2012). Electro-catalytic oxidative cleavage of lignin in a protic ionic liquid. Phys. Chem. Chem. Phys. [14], 5214-5221.

[59] George, A., Tran, K., Morgan, T. J., Benke, P. I., Berrueco, C., et al. (2011). The effect of ionic cation and anion combinations on the macromolecular structure of lignins. Green Chem. [13], 3375-3385.

[60] Bonilla, R. J., James, B. R., \& Jessop, P. G. (2000). Colloid-catalysedarene hydrogenation in aqueous/supercritical fluid biphasic media. Chem. Commun., 941-942. 
[61] Johnson, B. F. G. (1999). Coord. Chem. Rev., 1269-1285.

[62] Zhu, Y., Widjaja, E., Shirley, L. P. S., Wang, Z., Carpenter, K., Maguire, J. A., Hosmane, N. S., \& Hawthorne, M. F. (2007). J. Am. Chem. Soc., 129, 6507-6512.

[63] Karimi, B., Abedi, S., Clark, J. H., \& Budarin, V. (2006). Angew. Chem. Int. Ed., 45, 4776-4779.

[64] Parlett, C. M. A., Bruce, D. W., Hondow, N. S., Lee, A. F., \& Wilson, K. (2011). ACS Catal., 1, 636-640.

[65] Chen, Y., Zheng, H., Guo, Z., Zhou, C., Wang, C., Borgna, A., \& Yang, J. (2011). Catal., 283, 34-44.

[66] Zhu, Y., Li, C., Meriska, S., Ng, H. M., Algin, O. B., Maguire, J. A., \& Hosmane, N. S. (2012). Chem. OPEN, 1, 67-70.

[67] Denicourt-Nowicki, A., Léger, B., \& Roucoux, A. N. (2011). N-Donor ligands based on bipyridine and ionic liquids: an efficient partnership to stabilize rhodium colloids. Focus on oxygen-containing compounds hydrogenation. Phys. Chem. Chem. Phys. [13], 13510-13517.

[68] Mora-Pale, M., Meli, L., Doherty, T. V., Linhardt, R. J., \& Dordick, J. S. (2011). Room Temperature Ionic Liquids as Emerging Solvents for the Pretreatment of Lignocellulosic Biomass. Biotechnol. Bioeng. [108], 1229-1245. 